\title{
Analysis of the dynamic response of pump-turbine impellers. Influence of the rotor
}

\author{
Eduard Egusquiza ${ }^{\mathrm{a}, *}$, Carme Valero ${ }^{\mathrm{a}}$, Alex Presas ${ }^{\mathrm{a}}$, Xingxing Huang ${ }^{\mathrm{a}}$, \\ Alfredo Guardo ${ }^{\mathrm{a}}$, Ulrich Seidel ${ }^{\mathrm{b}}$ \\ a Center Industrial Diagnostics, Universitat Politècnica de Catalunya (UPC), Avinguda Diagonal 647, 08028 Barcelona, Spain

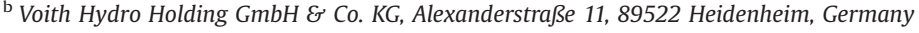

\section{A R T I C L E I N F O}

\section{Article history:}

Received 5 December 2013

Received in revised form

5 September 2014

Accepted 27 May 2015

\section{Keywords:}

Pump-turbine impellers

Dynamic response

Mode-shapes

FEM simulation

Experimental modal analysis

\begin{abstract}
A B S T R A C T
This paper deals with the dynamic response of pump-turbine impellers. A pump-turbine impeller is a complex structure attached to a rotor and rotating inside a casing full of water with very small clearances between the rotating and the stationary parts. The dynamic response of this type of structures is very complex and it is very much affected by the connection to the rotor as well as by the added mass and boundary conditions. As a consequence its calculation presents several uncertainties.

First, the dynamic response of pump-turbine impellers is introduced. Second an experimental investigation in a real impeller attached to the rotor and inside the machine was carried out. For this investigation, the impeller of an existing pump-turbine unit with an installed power of $110 \mathrm{MW}$ and a diameter of $2.87 \mathrm{~m}$ was studied. For a better analysis of the experimental results a numerical model using FEM was also built-up. Frequencies and mode-shapes were identified numerically and experimentally and the characteristics of the structural response analyzed.

To determine the influence of the rotor and supporting structures on the impeller response the results were compared with the ones obtained with the same impeller but suspended (non-connected to the rotor). Experimental and numerical simulation were also used for this case. The changes in the dynamic response due to the rotor connection were determined.

Finally the results obtained are compared with the results from other pump-turbine impellers of different designs and general conclusions about the dynamics of this type of structures are given.
\end{abstract}

(c) 2015 Elsevier Ltd. All rights reserved.

\section{Introduction}

With the increase of new renewables (wind, solar, and marine energy), pump-storage power plants are becoming more and more important for grid control. These power plants are used for the storage of the surplus of energy produced by other power plants when energy demand is low so that consumption and generation is always matched. The stored energy can be

\footnotetext{
* Corresponding author. Tel.: +3493 4016714; fax: +34 934015812

E-mail address: egusquiza@mf.upc.edu (E. Egusquiza).

URL: http://www.upc.edu/cdif (E. Egusquiza).
} 
delivered again to the electrical grid when demand is high. The future of renewables is tied directly to pump-storage which is the most effective technology for the storage of large amounts of energy.

Pump-storage power plants use pump-turbines which are reversible machines that can be operated as a pump and as a turbine. The impeller of a pump-turbine is a complex structure, very stiff and rotating inside a casing full of water with very small clearances between the impeller and the casing. Under these conditions the dynamic response of the impeller is very complex because it is affected by the added mass and damping of water, by the rotor to which it is connected and by the proximity of the casing walls. The hydrodynamic added mass and damping effects modify the natural frequencies and mode-shapes. The effects of all these parameters on the natural frequencies should be known at design stage in order to avoid operation at resonance conditions which would generate excessive stresses and fatigue damage.

With the trends to increase power concentration (head per stage), the pressure fluctuation induced by the rotor-stator interaction during the operation of the machine is large resulting in large dynamic forces on the impeller. If resonance occurs, damage can appear in the impeller and in fact, damage in this type of impellers was reported by several authors [13]. To avoid this kind of problem, it is of paramount importance to have an accurate understanding of the dynamic response of the impeller, especially when it is submerged in water.

For a structure with a complex geometry, such as a hydraulic turbine impeller, there is a limited number of studies available, performed in Francis impellers in air and in water but with simplified boundary conditions [4]. Other publications have presented detailed experimental and numerical analysis considering the effect of surrounding mass of water [5-7] but in a reduced scale model and without taking into account the boundary conditions of the casing. Other publications about dynamic behavior in Francis turbines [8] do not give details about the impeller response.

A pump-turbine impeller has a quite different design than a Francis turbine impeller. There are even fewer references available for this type of impeller, especially for a prototype. Some results in reduced-scale models and prototypes are available in air and water but without casing $[9,10]$. The frequency response of prototype impellers is shown in [11] but no details about the influence of boundary conditions are indicated. A reference publication in this field [12] gives a general view on the dynamic behavior of a prototype impeller but the impeller response shown is only in air. Detailed measurements of the dynamic response of pump-turbine impellers with real mounting conditions (connected to the rotor and inside the casing) have never been published.

In this paper the dynamic response of actual pump-turbine impellers is investigated. After introducing the general characteristics of a impeller response, an experimental investigation is carried out with the impeller in real mounting conditions, connected to the rotor and inside the casing. To determine the influence of the rotor connection the natural frequencies and mode-shapes obtained are compared with the ones of the same impeller but suspended (without the influence of the rotor). Numerical models were built-up and the numerical results were compared with the experimental data. In the paper a comprehensive analysis of the impeller dynamic characteristics is indicated showing the evolution of natural frequencies and mode-shapes. Finally the results are compared with the results obtained in other impellers and general conclusions are given. The paper is limited to the dynamic response of the impeller and the shaft response is not included. Rotating effects are not included either.

\section{Dynamics of a pump-turbine impeller}

\subsection{Modal behavior of disk-like structures}

The vibration modes of a cyclic symmetric structure can be classified according to the numbers of harmonic index $(k)$, nodal diameters $\left(N_{D}\right)$ and nodal circles $\left(N_{C}\right)$. The harmonic index $(k)$ is an integer that determines the variation in the value of a single degree of freedom (DOF) at points spaced at a circumferential angle equal to the sector angle. The following equation represents the relationship between the harmonic index $k$ and nodal diameter $N_{D}$ for a model consisting of $N$ sectors

$$
\begin{aligned}
& k=\left\{\begin{array}{l}
N / 2, \quad N \text { is even number } \\
(N-1) / 2, \quad N \text { is odd number }
\end{array}\right. \\
& N_{d}=m N \pm k ; m=0,1,2,3 \ldots \infty . \\
& \phi=\pi /(2 d)
\end{aligned}
$$

Defined by the condition $k=0$, the modes are singlet. These modes are independent of the angular coordinate $\theta$. The modes with $k \neq 0$ are doublet; they have a pair of mode shapes with the same natural frequency. Each member of such a pair has either sinusoidal or cosinusoidal $\theta$-dependent mode shape. The only difference between them is a spatial phase shift of $\phi$. Another parameter is the nodal circle $N_{c}$ that represents the number of circles with zero out-of-plane displacement in the structure $[13,14]$. 


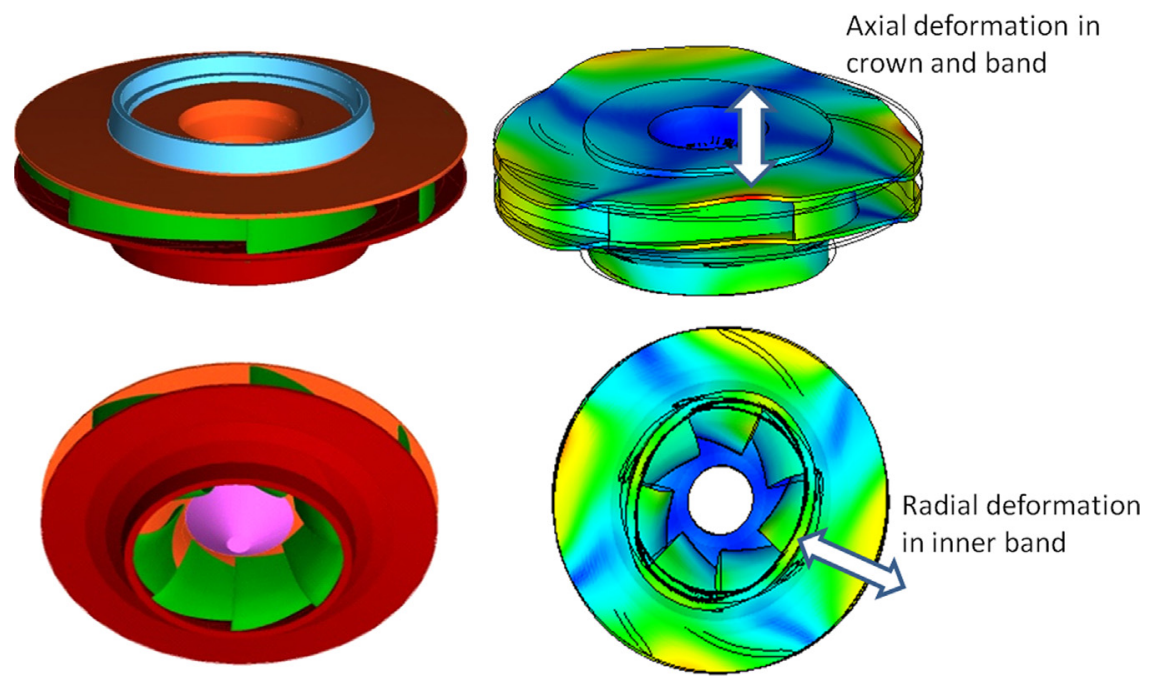

Fig. 1. Typical deformations in a pump-turbine impeller.

\subsection{Modal behavior of a pump-turbine impeller}

For a complex structure with cyclic symmetry (e.g., a hydraulic impeller) the dynamic behavior becomes entangled and the modal diameters may not be clearly observable in a mode shape. Moreover, due to the structural characteristics of pump-turbine impellers, the crown and band have much lower stiffness in the axial direction than the blades, especially near the outer diameter of the impeller. From a global point of view, it can be observed that the displacement is mainly in the outer diameter in axial direction. This part is very close to the guide vanes, receiving the main excitation due to the rotor-stator interaction phenomenon during the operation of the machine. Hence, it is also the position where damage may occur and its behavior is more interesting. There is also deformation in the inner diameter but in radial direction (Fig. 1)

Because of the odd number of cyclic sectors and the large span angle of each blade (around $180^{\circ}$ ), the global stiffness distribution is not smooth on the structure. Consequently, the main features cannot be clearly observed in some modeshapes, especially for the modes in higher frequency.

Therefore, with a singly specified value of $N_{D}$, several different modes, exhibiting different relative motions between the two parts, will exist. They may include the in-phase motion $(I P h)$, the counter-phase motion $(C P h)$, the crown-dominant motion $(C D)$, and the band-dominant motion $(B D)$. Though infinite modes exist theoretically, only some modes with lower natural frequencies are interesting from the engineering point of view, especially the ones with 2-ND and 3-ND because these are the ones more prone to be excited by the pressure pulsations when the machine is in operation [12,15,16].

\section{Dynamics of the impeller attached to the rotor}

In the machine, the impeller is fixed to the rotor shaft through a bolt coupling. The connection between impeller and rotor affects the dynamics of the whole system. To determine the influence of the rotor on the dynamic response of the impeller an experimental and a numerical investigation were carried out. The results were compared with the dynamic response of the impeller without rotor connection.

\subsection{Machine description}

For this study the impeller of an existing machine was selected. The machine is a vertical shaft pump-turbine unit with the electrical motor/generator in the upper part and the turbine in the lower part (Fig. 2a). For pump operation, the design head is $H=382 \mathrm{~m}$, the flow rate $Q=24 \mathrm{~m}^{3} / \mathrm{s}$ and the power $W=97.7 \mathrm{MW}$. For turbine operation $H=370 \mathrm{~m}, Q=31.25 \mathrm{~m}^{3} / \mathrm{s}$ and $W=104 \mathrm{MW}$. Geometrical details of the impeller were provided by the manufacturer and the plant operator granted permission for the tests.

The tested impeller is the rotating part of the pump-turbine with a rotating speed of $600 \mathrm{rpm}$; it has 7 blades and an external diameter of $2.870 \mathrm{~m}$ with a weight of $10200 \mathrm{~kg}$. The number of guide vanes around the impeller is 16 . The impeller is a disk-like structure with two disks (called the crown and the band). The impeller blades are located between these two disks (Fig. 2b). The impeller is made of G-X3CrNi13.4; the material properties are shown in Table 1. 

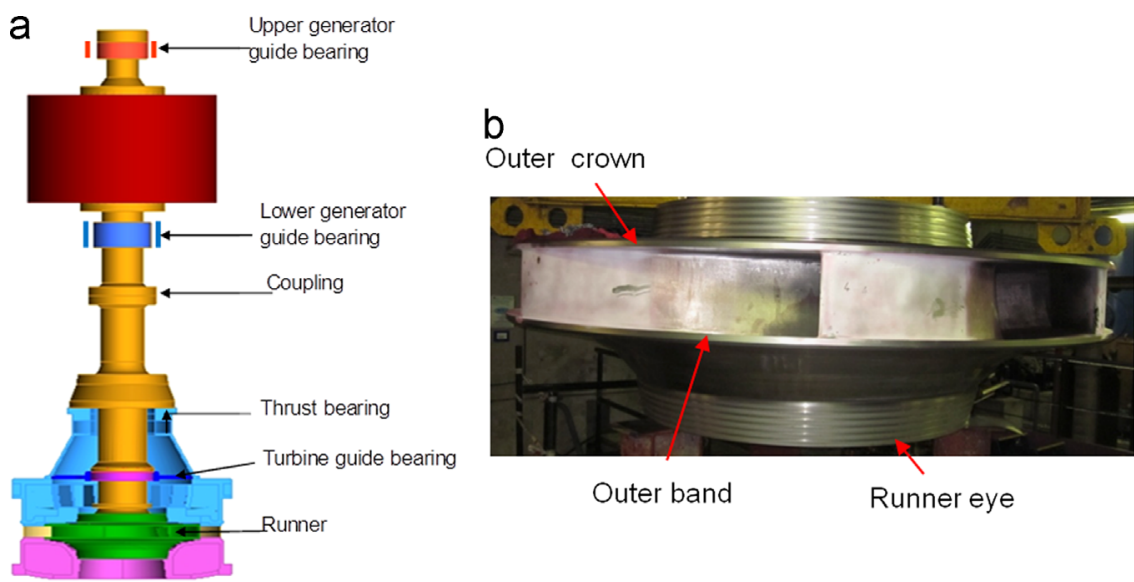

Fig. 2. (a) Sketch of the hydropower unit; and (b) picture of the impeller.

Table 1

Properties of the impeller material.

\begin{tabular}{llll}
\hline Properties & Young's modulus & Density & Poisson's ratio \\
\hline Value & $205 \mathrm{GPa}$ & $7700 \mathrm{~kg} / \mathrm{m}^{3}$ & 0.30 \\
\hline
\end{tabular}

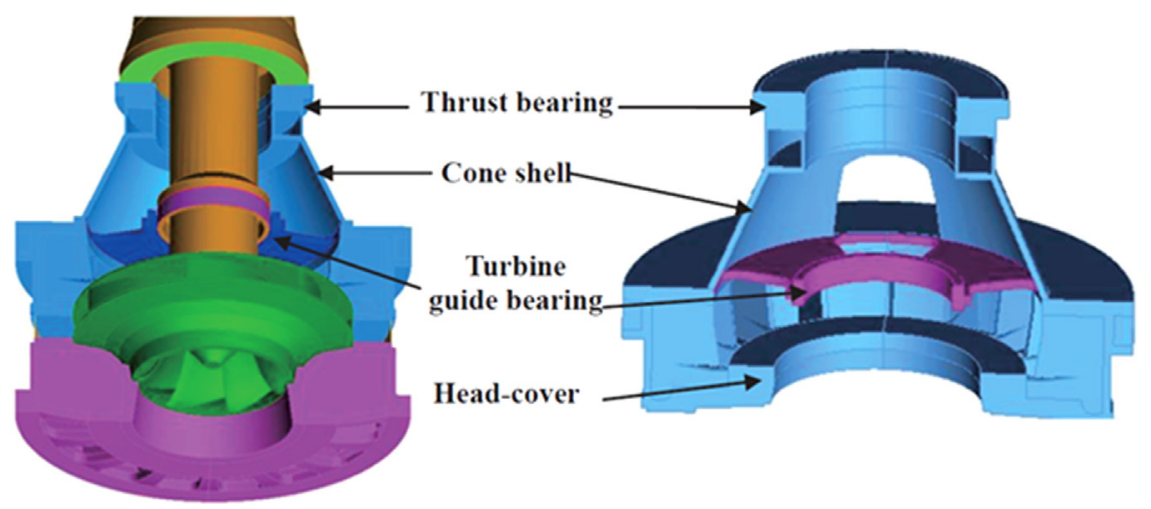

Fig. 3. Head cover and bearing support structure.

\subsection{Numerical simulation}

For the simulation a FEM numerical model of the whole machine was generated. The hydropower unit has two main components: the electrical machine (generator) and the hydraulic machine (turbine), connected by a rigid coupling. The complete rotating system is composed of a shaft with a generator at one side and the impeller at the other side. Three radial bearings and one axial bearing are the support of the rotor (see Fig. 2a). The structure supporting the thrust bearing and the turbine bearing can be shown in Fig. 3. The other bearings (lower and upper generator bearings) are connected directly to the concrete structure by a rigid structure. Because the head-cover structure can have significant effects on the dynamic response of the system it was included in the simulation (Fig. 3). In the parts of the head-cover structure connected to the concrete structure (shown in red color in Fig. 4) it was considered a complete restriction of motion in axial direction. For the other bearings the stiffness coefficients were estimated and imposed in the numerical model. For the upper generator bearing the bearing stiffness selected was $10^{9} \mathrm{~N} / \mathrm{m}$ and for the lower generator bearing $2.4 \times 10^{9} \mathrm{~N} / \mathrm{m}$.

High order tetrahedral elements were used to obtain a high quality mesh of the structure for the numerical calculation. A finer mesh density was used in the impeller and surrounding structure. Sensitivity analysis of the mesh density showed that a mesh of about 200000 elements is enough to have converged values. A finite element model of the structure with 206,500 elements was adopted to perform the simulation (Fig. 4). The results obtained with the numerical model will be discussed later. 

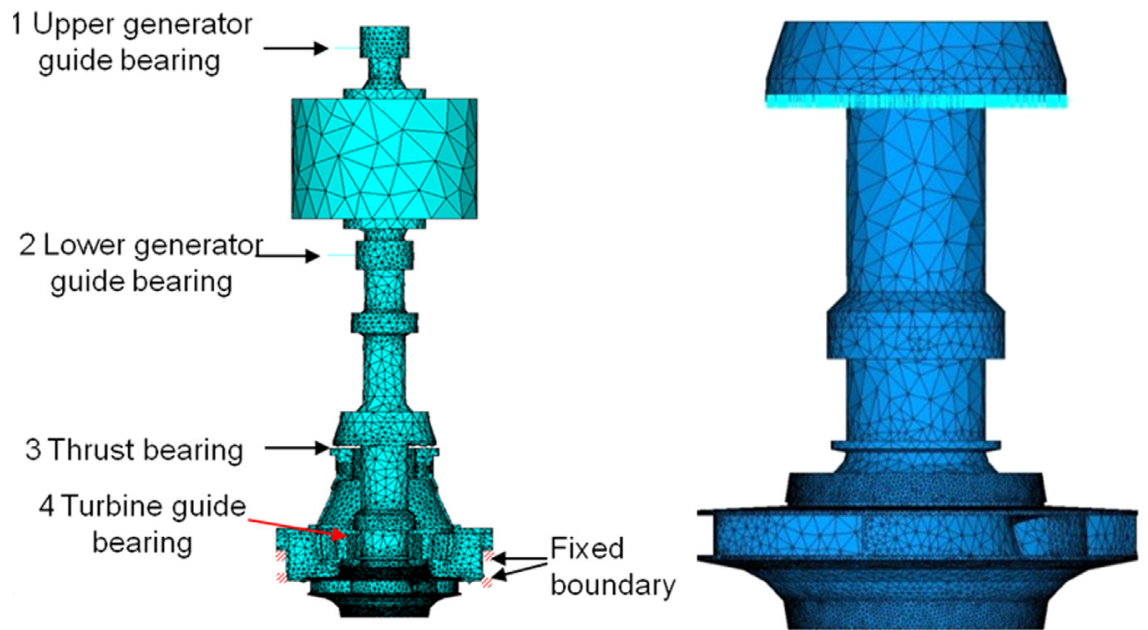

Fig. 4. FEM model of the impeller and rotor. (For interpretation of the references to color in this figure, the reader is referred to the web version of this article.).

\section{Experimental tests}

\subsection{Equipment}

Taking advantage of a scheduled plant stop for a technical inspection of the machine, a complete measurement on the impeller and shaft was carried out. The impeller was open and accessible; several sensors could be installed on it. The impeller was now in real conditions, that is, attached to the rotor and inside the casing.

Fig. 5 shows some of the sensors used and its location in the impeller. Sensors were located on the crown, band and eye so that the main mode-shapes could be identified. The sensors used were ICP accelerometers Kistler with a dynamic range of $\pm 50 \mathrm{~g}$, a sensitivity of $100 \mathrm{mV} / \mathrm{g}$ and a resonant frequency of $30 \mathrm{kHz}$. The signals were recorded in a multichannel acquisition system Pulse of B\&K.

Impact test were carried out hitting the impeller in different locations with an instrumented hammer. Impacts were done on the impeller in the axial and radial directions changing the position of the impact points for a proper identification of the natural frequencies and mode-shapes. Impacts were also performed on the shaft and head cover.

Fig. 6 shows the spectra of the signals captured by the accelerometers located on the crown and on the band when the impeller was excited by the hammer. For frequencies below $250 \mathrm{~Hz}$ no large response was observed, for frequencies higher than $1 \mathrm{kHz}$ the observed response is at minimum values. Two frequency ranges with maximum response are identified in the crown spectra while another frequency range can be observed in the response of the band.

\subsection{Natural frequencies and mode-shape identification}

Using several experimental modal analysis techniques (EMA) the natural frequencies were clearly identified. The first two peaks in the spectra are found at $291 \mathrm{~Hz}$ and $448 \mathrm{~Hz}$. In Fig. 7, the FRF in amplitude/phase, the results of the CMIF (complex mode indicator function) and of the stability diagrams for these peaks are represented.

For a better identification of the frequencies, the mode-shapes calculated numerically were compared with the modeshapes obtained experimentally. Operating deflection shapes were used to determine the mode-shapes and visualize the structure motion. Fig. 8 shows the comparison between the numerical results and the experimental results for the first eigenfrequency found $(291 \mathrm{~Hz})$. This eigenfrequency corresponds to a 2-ND mode with strong axial deformation in the crown and in the band; both move in phase with similar deformation. The mode-shape also presents a strong radial deformation in the impeller eye. Numerical and experimental results show good agreement.

In Fig. 9, the second eigenfrequency found at $446.5 \mathrm{~Hz}$ can be observed. This corresponds to a 3-ND mode also with strong deformation. Crown and band move in phase with more deformation in the crown than in the band. A clear 3-ND pattern can be seen in the deformation of the eye.

\section{Discussion of results}

Taking into account the complex behavior of the impeller and after the validation of the simulation at the first natural frequencies found, a deeper analysis using the experimental results and the numerical simulation was carried out. The experimental FRF comparing the response of accelerometers located in different positions to impacts on different parts of 

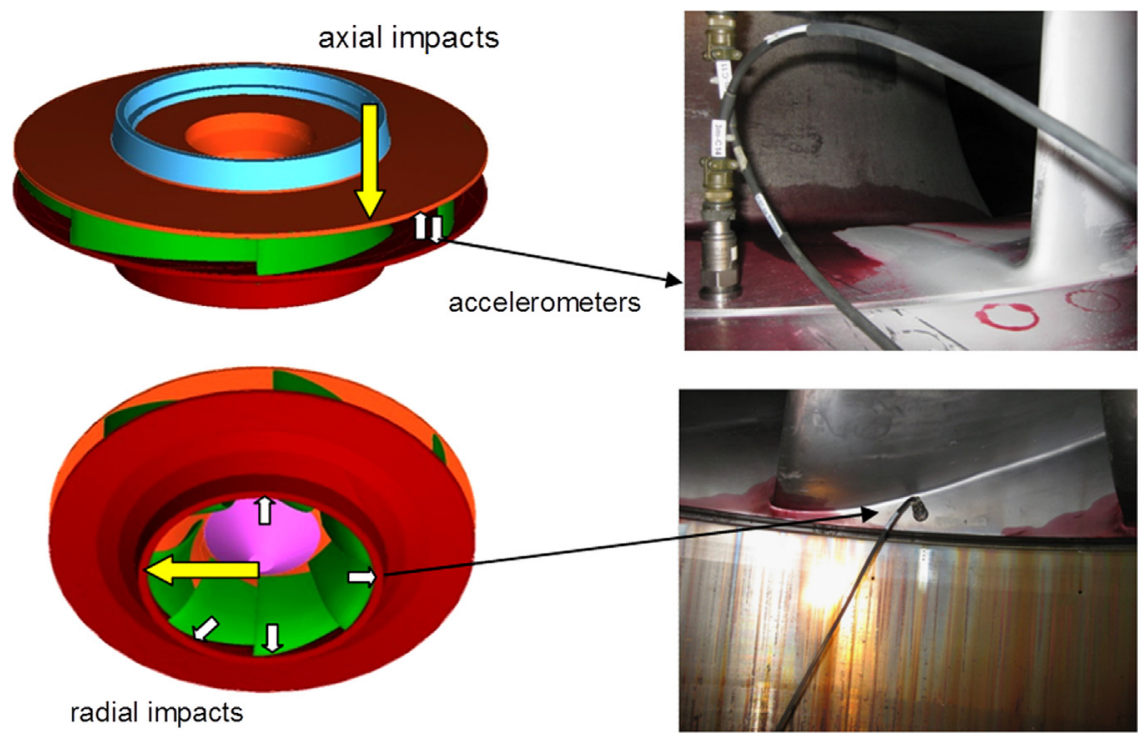

Fig. 5. Testing positions. Top: sensors located axially on the outer crown and band; bottom sensors located radially on the impeller eye.

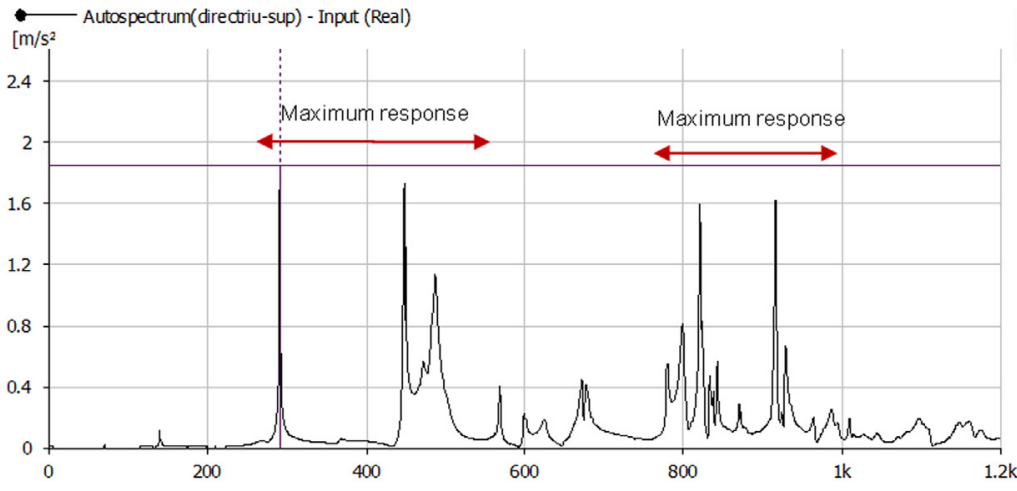

Cursor values

$X: 291.000 \mathrm{~Hz}$

$\mathrm{Y}: 1.848 \mathrm{~m} / \mathrm{s}^{2}$

$[\mathrm{Hz}]$

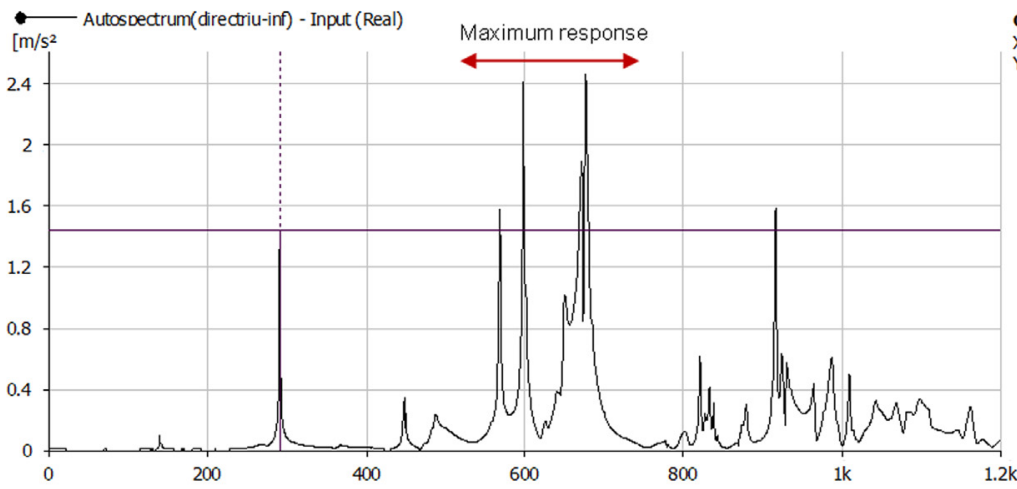

$[\mathrm{Hz}]$

Fig. 6. Spectra of vibrations measured in the crown (above) and in the band (bellow) to radial impacts on impeller eye.

the impeller were compared with the results of the numerical FEM model. Using both it was possible to understand the complex modal behavior of this impeller.

In Fig. 10, the FRF of the accelerometers located axially in the in the crown and in the band to hammer impacts on the impeller eye is shown. In Fig. 11, the radial response of the impeller in the eye is also represented. With the axial and radial response in the impeller the complex response can be analyzed and compared with the simulation results. Taking a look at 

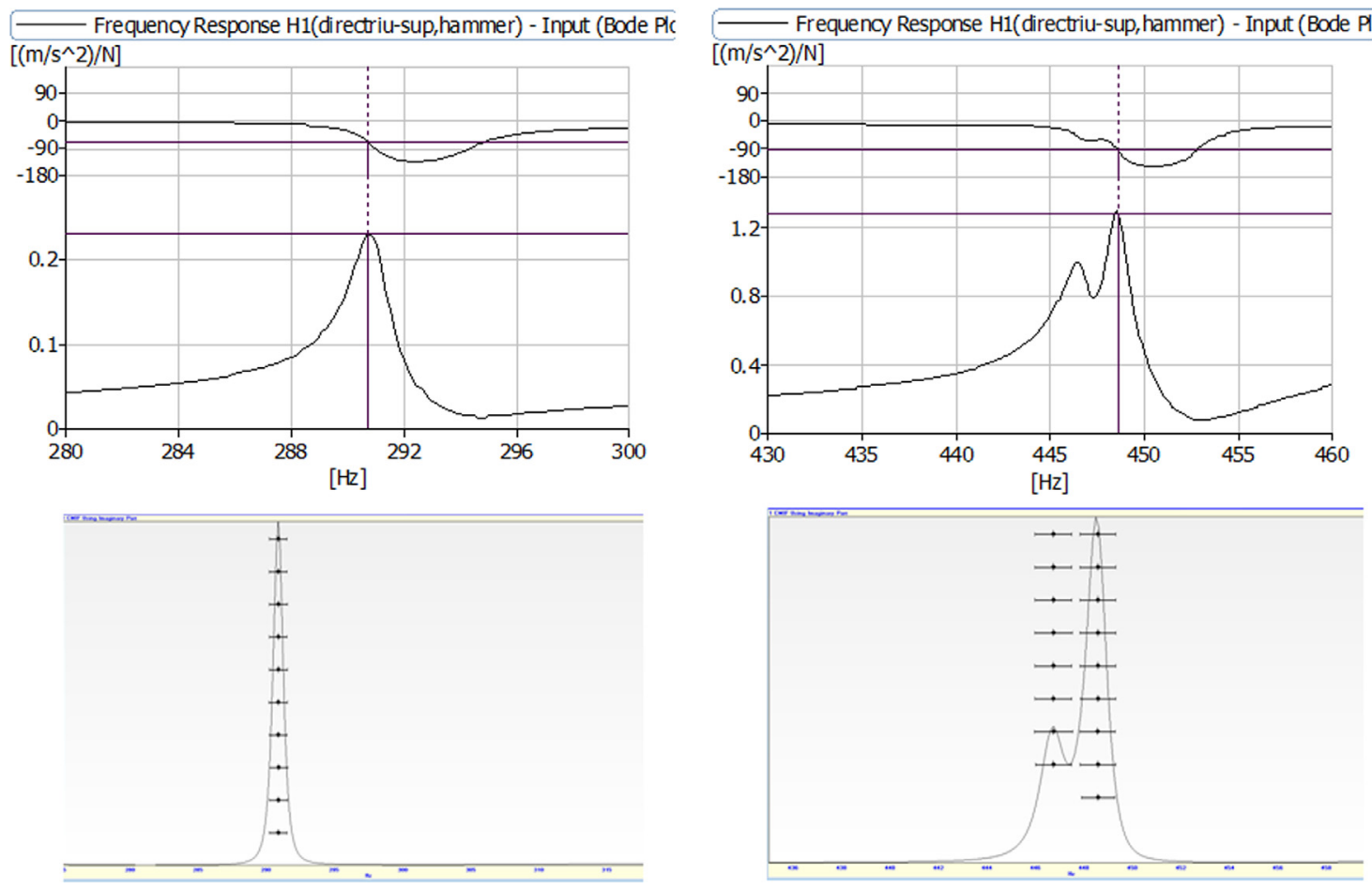

Fig. 7. Identification of the natural frequency at $291 \mathrm{~Hz}$ and at $446.5 / 448.5 \mathrm{~Hz}$.

\section{Numerical simulation experimental results}

a

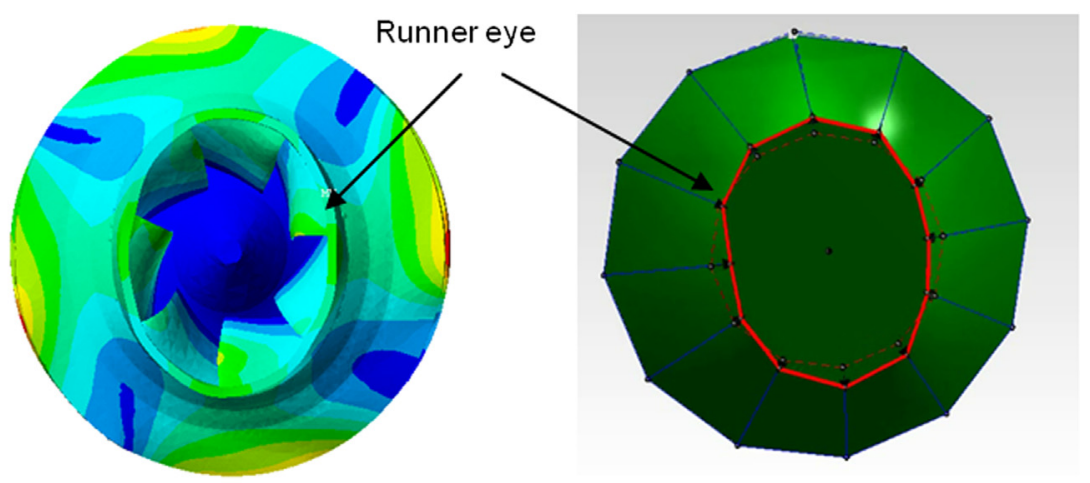

b

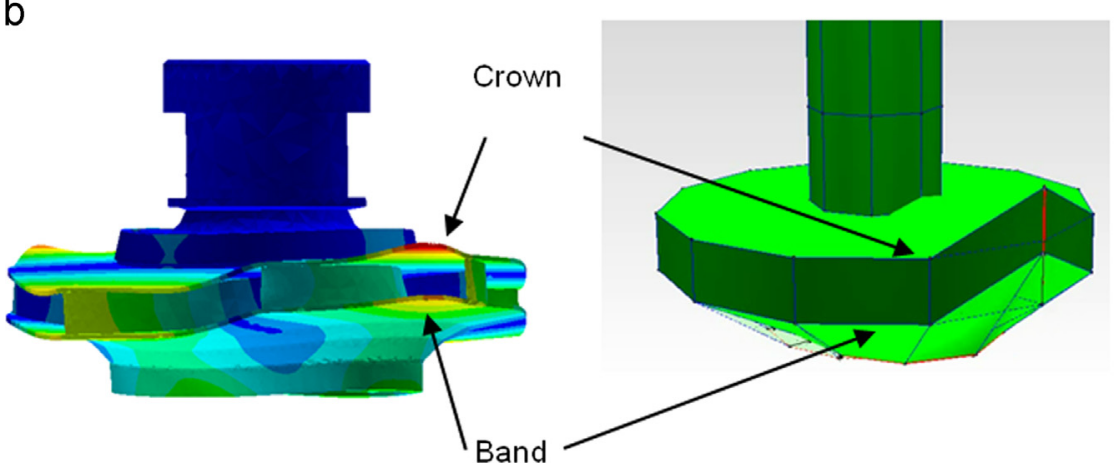

Fig. 8. View of the impeller deformation at 2-ND natural frequency (291 Hz): simulation and experiment. (a) Deformation of the impeller eye; and (b) deformation of the crown and band.

Please cite this article as: E. Egusquiza, et al., Analysis of the dynamic response of pump-turbine impellers. Influence of the rotor, Mech. Syst. Signal Process. (2015), http://dx.doi.org/10.1016/j.ymssp.2015.05.034 


\section{Numerical simulation experimental results}
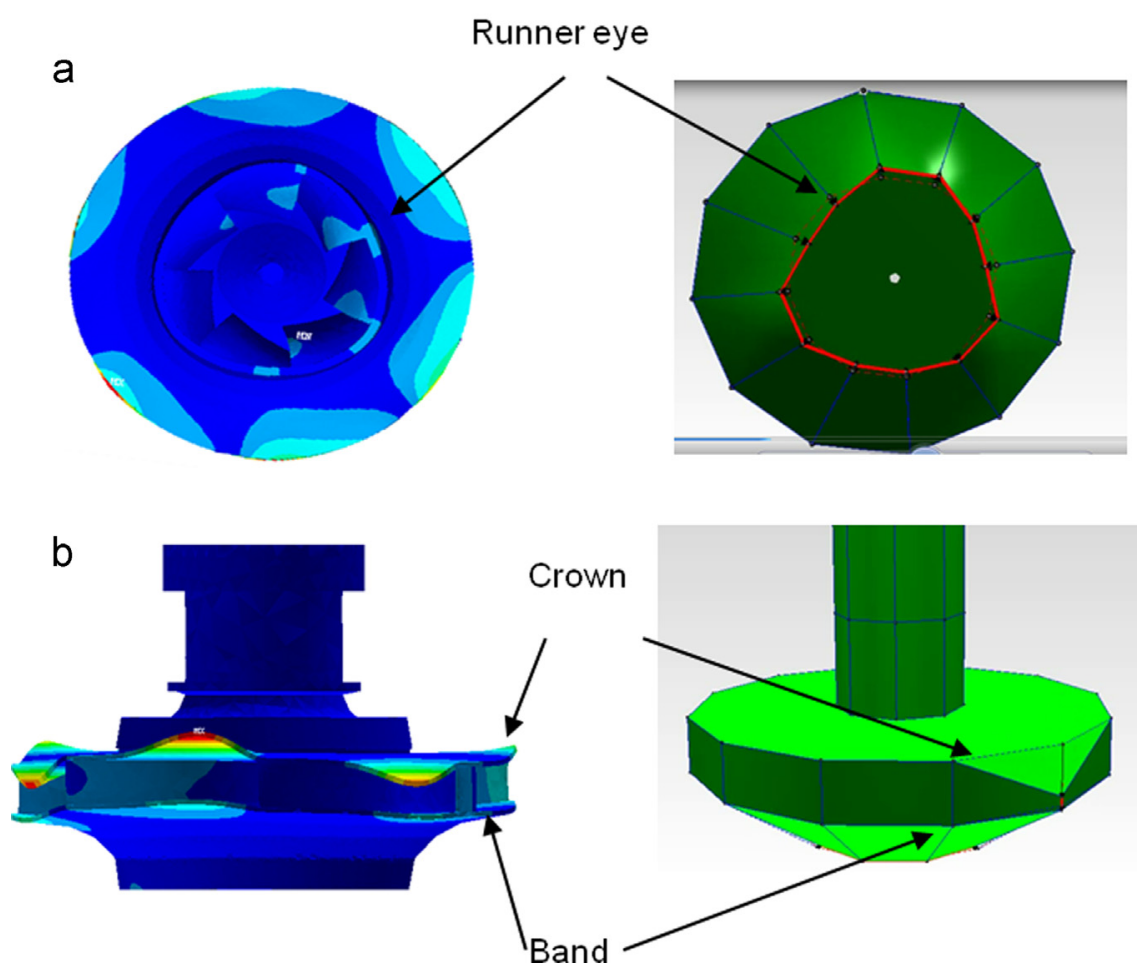

Fig. 9. View of the impeller deformation at 3-ND natural frequency in-phase $(447 \mathrm{~Hz})$ : simulation and experiment. (a) Deformation of the impeller eye; and (b) deformation of the crown and band.

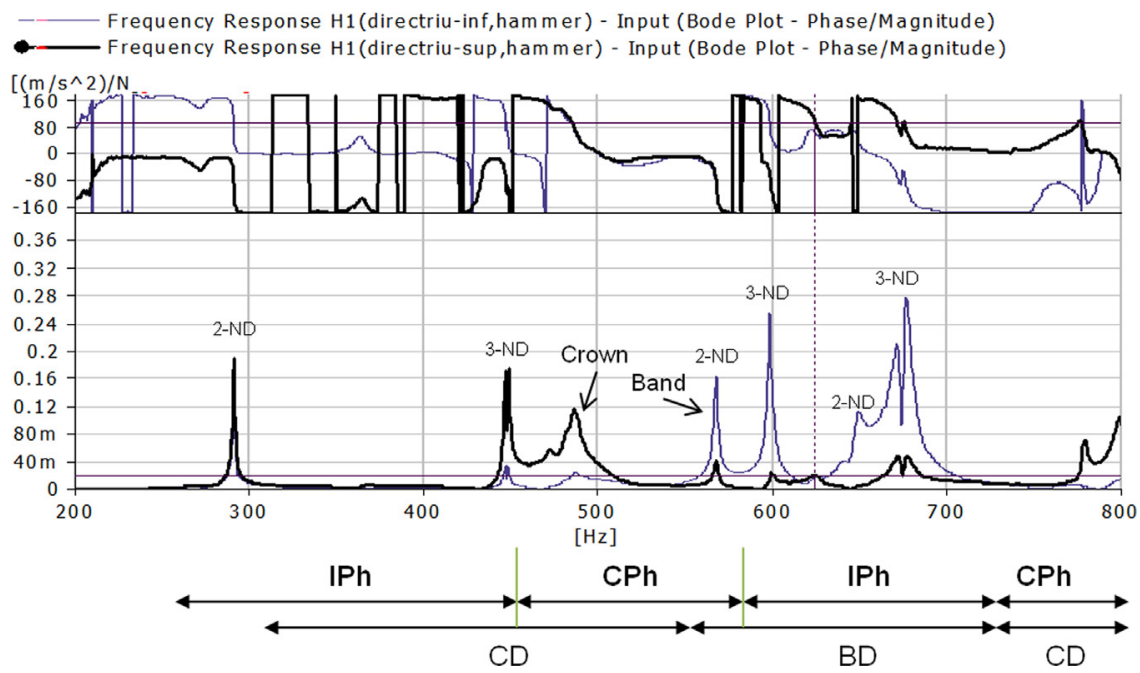

Fig. 10. Axial impeller response in the crown (blue line) and in the band (black line) to radial impacts (on impeller eye). (For interpretation of the references to color in this figure legend, the reader is referred to the web version of this article).

Fig. 10, different frequency ranges can be observed in the response of the crown and of the band depending on the modeshape characteristics

- A first one from $250 \mathrm{~Hz}$ to $550 \mathrm{~Hz}$ where crown deformation is generally predominant (CD).

- A second from $550 \mathrm{~Hz}$ to $720 \mathrm{~Hz}$ where band deformation is predominant (BD).

- From $720 \mathrm{~Hz}$ crown deformation is predominant again (CD). 


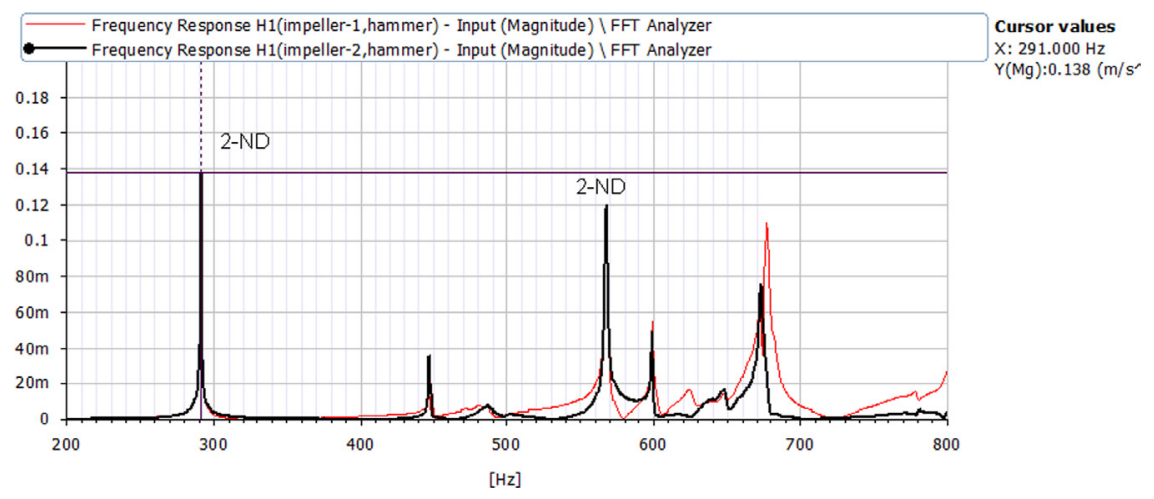

Fig. 11. Radial response in the impeller eye to radial impacts on the same impeller eye.

Several natural frequencies are identified corresponding to different mode-shapes. Natural frequencies with modeshapes of zero and one nodal diameters (0-ND and 1-ND) can hardly be seen in the FRF figures. These modes are affected by the rotor dynamics especially at low frequencies and, in these cases, the energy of the impacts has to deform both impeller and rotor giving a lower response. According to the rotor-stator interaction (RSI) which is the main excitation force on the impeller, with the present machine designs only modes with two (2-ND) and higher nodal diameters can be excited $[15,16]$.

The response of the modes with 2-ND and higher have a larger response and can be seen as sharp peaks in the FRF functions. In these natural frequencies the rotor is not involved in the deformation and all the energy of the impacts is used to deform only the impeller. Because the excitation generated by the rotor stator interaction during the operation of the machine has typically two or more nodal diameters only mode-shapes with 2-ND or higher are interesting for the analysis of the dynamic behavior of the machine.

As indicated above, the first mode-shape detected with large response is a 2-ND mode which is a doublet mode with repeated frequencies. The peak is identified in Fig. 10 in the crown and in the band axial vibration and also in the radial vibration of the impeller eye (Fig. 11). This corresponds to the simulation shown in Fig. 8 where deformation in crown, band and eye can be seen. Crown and band move in-phase and there is a strong deformation in the impeller eye.

The second is a 3-ND mode, also a doublet mode with repeated frequencies; three irregular nodal diameters can be observed on both crown and band. The crown and the band move in-phase with larger deformation in the crown than in the band. There is also a large deformation in the impeller eye (see Figs. 9 and 11). Both 2-ND and 3-ND are completely separated in frequency and do not affect each other.

From $450 \mathrm{~Hz}$ to $550 \mathrm{~Hz}$ the response is not so peaky and several eigenfrequencies with high modal density can be observed. In this zone there is a change in the mode-shape characteristics and all the deformation occurs especially in the crown with circumferential asymmetric deformation. Now crown and band are deforming in counter-phase $(\mathrm{CPh})$ and the deformation in the impeller eye is very small as can be seen in Fig. 11. Natural frequencies with 2-ND and 3-ND mode-shapes are found in this part of the FRF.

This behavior changes again in the range from $550 \mathrm{~Hz}$ to $720 \mathrm{~Hz}$. In this range the crown and the band move in-phase again and the deformation is larger in the band than in the crown. At $567 \mathrm{~Hz}$ there is a clear 2-ND mode-shape with strong deformation in the band and impeller eye. At $599 \mathrm{~Hz}$ other eigenfrequencies are found with an asymmetric response and only with the participation of the band. At $677 \mathrm{~Hz}$ a mode with a general deformation especially in the band and in impeller eye is found with a 3-ND mode-shape.

Finally after $720 \mathrm{~Hz}$, there is another change in the modal behavior with strong deformations in the crown and counter-phase deformations. Crown dominated deformations occur until $823 \mathrm{~Hz}$ where complex mode-shapes with strong deformation in the crown and in the blades can be found.

In Fig. 12, the mode-shapes of the most important natural frequencies found are represented. From the analysis of the mode-shapes some general conclusions can be extracted.

In the first natural frequencies found the mode-shapes are disk-like modes having rather clear diametrical nodes. The motion affects the whole impeller with deformation in the crown, band and eye. Crown and band deform in-phase. When increasing frequency the response in the crown increases while in band decreases reaching frequencies where the deformation occurs only in the crown. The deformation occurs only in local parts of the crown and the relative motion between crown and band starts to be in counter-phase. Except in the first mode, in all this frequency range there is a crown dominant (CD) motion.

When increasing frequency again the participation of the crown decreases while the band deformation increases. A global mode is found at $567 \mathrm{~Hz}$ with large deformation in crown, band and eye in counter-phase. At $595 \mathrm{~Hz}$ another mode is found but now with the maximum deformation in the band; crown and band start to move in-phase. At higher frequencies a double flexion appears in the crown between blades. Blade modes are in this region.

All these characteristics are summarized in Table 2 regarding

- The location with maximum deformation

- Crown dominating (CD); Band dominating (BD).

- The relative axial deformation between crown and band: in phase (IPh); in counter-phase (CPh). 

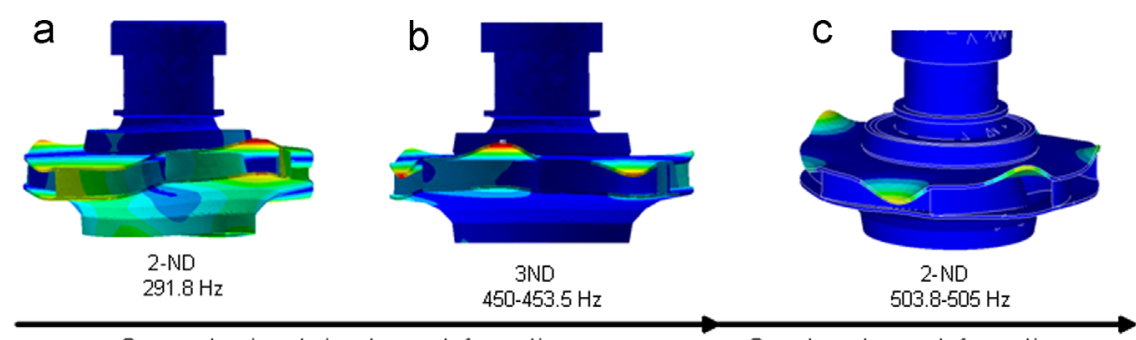

Crown dominant, in-phase deformation Decreasing participation of the band

Counter-phase deformations
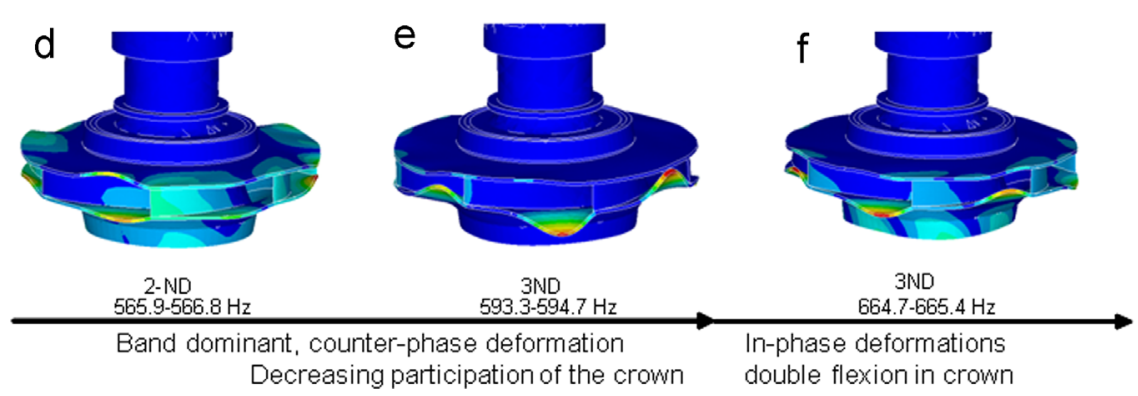

Fig. 12. Evolution of mode-shape characteristics. Deformations are enlarged.

Table 2

Impeller response characteristics of the main 2-ND and 3-ND modes.

\begin{tabular}{|c|c|c|c|c|}
\hline $\begin{array}{l}\text { Frequency } \\
\text { Experiment }\end{array}$ & $\begin{array}{l}\text { Frequency } \\
\text { Simulation }\end{array}$ & Mode & Comments & \\
\hline $291 \mathrm{~Hz}$ & 291.8 & 2-ND & Mode with large deformation in crown, band and eye; In-phase motion between crown and band & IPh, \\
\hline 447 & 450 & 3-ND & Mode with large deformation in crown and small deformation in band and eye; in-phase motion & $\mathrm{CD}$ \\
\hline 449 & 453.5 & & & IPh, \\
\hline \multirow[t]{2}{*}{568} & 565.9 & 2-ND & Mode with deformation in crown and band; deformation also in the eye; counter-phase motion & CPh, \\
\hline & 566.8 & & & \\
\hline \multirow[t]{2}{*}{598.5} & 593.3 & 3-ND & Mode with very small deformation in crown and large deformation in band; counter-phase & BD, \\
\hline & 594.7 & & motion & IPh \\
\hline 672 & 664.7 & 3-ND & Mode with small deformation in crown, large deformation in band and eye; in-phase motion; & BD, \\
\hline 676 & 665.4 & & double flexion in crown & CPh \\
\hline
\end{tabular}

\subsection{Comparison with the same impeller but without rotor connection}

In Fig. 13, the modal response of the same impeller but suspended without rotor has been represented. When comparing the response with and without rotor some changes can be seen. The connection to the rotor produces a shift in the first frequency values; the first 2-ND mode has increased his frequency from $250 \mathrm{~Hz}$ to $291 \mathrm{~Hz}$ (1.16\%) while the 3-ND increases from $437 \mathrm{~Hz}$ to $447 \mathrm{~Hz}$ (1.03\%). This is because the shaft connection increases the stiffness of the crown. Another difference is with the 0-ND and 1-ND modes. While these modes could hardly be seen in the frequency response function when the impeller was connected to the rotor, with the impeller suspended they are clearly detected. As indicated above, while the modes 2-ND and higher are little affected by the rotor the 0-ND and 1-ND are much affected. In that case the impacts on the impeller have not energy enough to excite the whole rotor system and the response is very small. Moreover the 0-ND and 1ND modes are very much affected by the lateral natural frequencies of the rotor and cannot be compared with the response of the sole impeller. Higher modes show very little changes in frequency but the amplitude of the response is modified by the response of the structure. The evolution of modes is the same in both cases (with and without rotor), first modes inphase followed by modes in counter-phase.

\subsection{Comparison with other impellers}

To provide a more general perspective of the response of these impellers, the results are compared with the ones obtained in other impellers of different designs. These impellers are one of 6 blades [12] and another of 9 blades [9]. The 


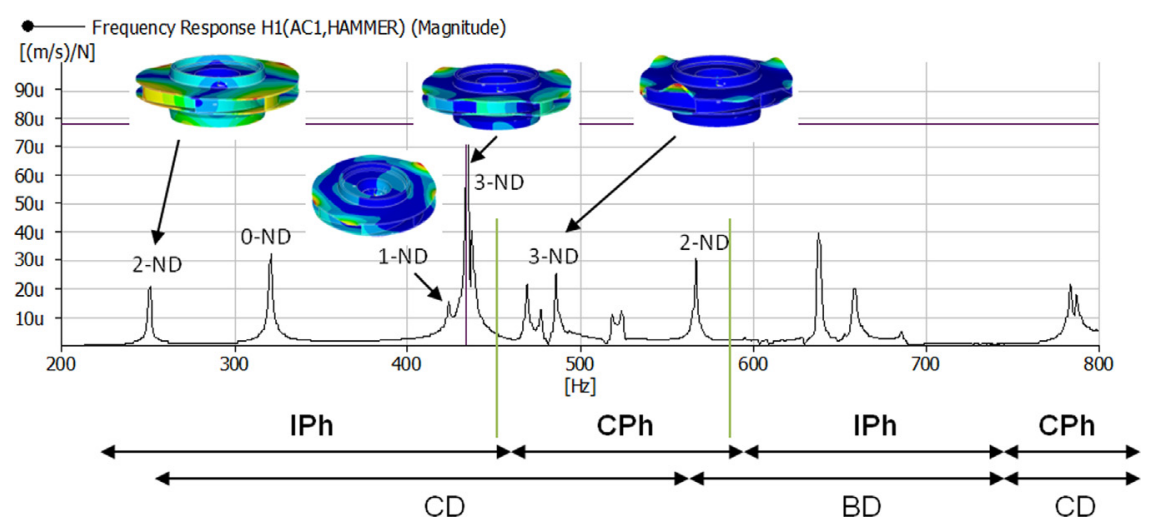

Fig. 13. Evolution of mode-shape characteristics. Impeller without rotor.

Table 3

First modes found in different impellers.

\begin{tabular}{lllll}
\hline Mode & Frequency $(\mathrm{Hz})$ & & Phase crown-band \\
\cline { 2 - 5 } & Runner 7 blades $(2.87 \mathrm{~m})$ & Runner 6 blades $(3.76 \mathrm{~m})[12]$ & Runner 9 blades $(0.53 \mathrm{~m})[9]$ & IPh=In phase CD=Crown dominant \\
\hline 2-ND & 250 & 187 & 838 & IPh \\
0-ND & 336 & 259 & 1111 & IPh; CD \\
1-ND & 431 & 330 & 1439 & IPh; CD \\
3-ND & 437 & 294 & 1463 & IPh; CD \\
\hline
\end{tabular}

response characteristics of all the impellers have some similarities. The first modes found have a disk-like mode-shape with crown and band deforming in-phase and in general the deformation is crown dominant (more deformation in the crown than in the band). In a second frequency range crown and band are in counter-phase followed by in-phase motions again. Also in all cases the first natural frequency found has a 2-ND mode-shape followed by a 0-ND mode-shape. In Table 3 the values are compared.

\section{Conclusions}

The dynamic response of a pump-turbine impeller was studied. An experimental investigation and a numerical simulation were used to understand the characteristics of the response. The natural frequencies and associated modeshapes were identified, analyzed and classified according to their nodal diameters and modal behavior. For a complex structure like this type of impellers, the modal response is complex exhibiting many natural frequencies with entangled mode-shapes. The main classification is carried out according the nodal diameters although sometimes they are not clearly observable in the mode-shape.

Due to the structural characteristics, the crown and band have much lower stiffness in the axial direction compared with the blades, especially near the outer diameter of the impeller in the suction side. Therefore the deformation is mainly in the outer diameter in axial direction. The impeller eye also deforms but in radial direction.

From the investigation carried out in an actual impeller installed in a machine some trends can be extracted. Depending on the mode-shape characteristics different frequency bands can be identified in the impeller response. In the first frequency range (250-550 Hz in the investigated impeller) the mode-shapes have more deformation in the crown than in the band (crown dominant motion) except in the first mode-shape. This frequency range can be split into two parts one with disk-like in-phase motions between crown and band and another with counter-phase motions. Up to $450 \mathrm{~Hz}$ the motion of crown and band are in-phase and from $450 \mathrm{~Hz}$ to $670 \mathrm{~Hz}$ are in counter-phase.

In the beginning of this range clear and separated natural frequencies (2-ND and 3-ND modes) are found with an inphase motion and the whole impeller deforming. In the counter-phase frequency range higher modal density exists and, in general, only one part of the impeller deforms (basically the crown) with asymmetric deformation around the impeller.

In a second frequency range the deformation occurs basically in the band (band dominant) with in-phase and counterphase motions. After that the deformation occurs again in the crown with more complex modes and blade deformations.

The numerical model gives a rather good accuracy. Comparing these results with other published cases all impellers follow a similar pattern: first modes are disk-like with crown and band deforming in phase. When increasing frequency the deformation in band decreases and the crown and band deforms in counter-phase. Finally crown and band deforms again in-phase but with more deformation in band than in crown. The effect of the rotor on the impeller natural frequencies with 2-ND and 3-ND modes is to increase a little their frequency value in the first modes. 


\section{Acknowledgments}

The authors would like to acknowledge Ministerio de Economia y Competitividad (Spain) Project DPI-2012-36264 and to Voith Hydro Holding GmbH \& Co. KG for their collaboration.

\section{References}

[1] E. Egusquiza, C. Valero, X. Huang, E. Jou, A. Guardo, C. Rodriguez, Failure investigation of a large pump-turbine runner, Eng. Fail. Anal. 23 (2012) $27-34$.

[2] H. Ohashi, Case study of a pump failure due to rotor-stator interaction, Int. J. Rotating Mach. 1 (1) (1994) 53-60pp 1 (1994) 53-60.

[3] Y. Ohura, M. Fujii, O. Sugimoto, H. Tanaka, I. Yamagata, Vibration of the powerhouse structure of a pumped storage power plant, in: Proceedings of the 15th IAHR Symposium, Belgrade, 1990.

[4] M. Dubas, M. Schuch, Static and dynamic calculation of a francis turbine runner with some remarks on accuracy, Comput. Struct. 27 (5) (1987) 645-655.

[5] Q.W. Liang, et al., Modal Response of Hydraulic Turbine Runners, in: Proceedings of the 23rd IAHR Symposium, Yokohama, 2006.

[6] C.G. Rodriguez, et al., Experimental investigation of added mass effects on a francis turbine runner in still water, J. Fluids Struct. 22 (5) (2006) 699-712.

[7] Q.W. Liang, et al., Numerical simulation of fluid added mass effect on a francis turbine runner, Comput. Fluids 36 (2007) $1106-1118$.

[8] Stefan Lais, Quanwei Liang, Urs Henggeler, Thomas Weiss, Xavier Escaler, Eduard Egusquiza. Dynamic analysis of Francis runners - experiment and numerical simulation, in: Proceedings of the IAHR Brasil 24th Symposium on Hydraulic Machinery and Systems, 2008.

[9] X. Escaler, J.K. Hütter, E. Egusquiza, M. Farhat and F. Avellan. Modal behavior of a reduced scale pump-turbine impeller. Part 1: Experiments, in: Proceedings of the 25th IAHR Symposium on Hydraulic Machinery and Systems IOP Conference Series: Earth Environ. Sci., 2010, 12 , p. 012116.

[10] C. Valero, X. Huang, E. Egusquiza, M. Farhat and F. Avellan Modal behaviour of a reduced scale pump-turbine impeller. Part 2: numerical simulation, in: Proceedings of the 25th IAHR Symp. on Hydraulic Machinery and Systems, 20-24 September, Timisoara, Romania, 2010.

[11] E. Egusquiza, C. Valero, Q. Liang, M. Coussirat, U. Seidel Fluid added mass effect in the modal response of a pump-turbine runner ASME DETC200986830

[12] H. Tanaka Vibration behaviour and dynamic stress of runners of very high head reversible pump-turbines, in: Proceedings of the 15th IAHR Symposium, Belgrade, 1990.

[13] D.L. Thomas, Dynamics of rotationally periodic structures, Int. J. Numer. Methods Eng. 14 (1) (1979) 81-102.

[14] O.C. Zienkiewicz, F.C. Scott, On the principle of repeatability and its application in analysis of turbine and pump runners, Int. J. Numer. Methods Eng. 4 (3) (1972) 445-450.

[15] Pulpitel L., et al. Comments to vibrations and pressure oscillations induced by the rotor stator interaction in a hydraulic turbine, in: Proceedings of the 3rd Intern IAHR Workshop on cavitation and Dynamic problems in Hydraulic Machinery and Systems, 14-16 October, Brno, 2009.

[16] G. Franke, C. Powell, U. Seidel, J. Koutnik, R. Fisher, On pressure mode shapes arising from rotor stator interaction, in: Proceedings of the IAHR Working Group 1 meeting, Stuttgart, Germany, October, 2003. 